\title{
EDUCAÇÃO DESINTERESSADA E A ANÁLISE DE POLÍTICAS EDUCACIONAIS
}

\begin{abstract}
Simone Fátima Flach ${ }^{1}$ Anita Helena Schlesener ${ }^{2}$

\section{Resumo}

Este texto tem por objetivo apresentar o pensamento de Antonio Gramsci sobre a educação desinteressada para a formação integral dos estudantes com o intuito de contribuir para a análise de propostas, de programas e de projetos educacionais em curso nas políticas brasileiras. Para tanto, a partir de pesquisa bibliográfica, resgatam-se e interpretam-se os escritos do pensador sardo de forma a evidenciar a necessidade de uma educação desinteressada que contribua para a superação da atual organização social baseada na exploração do homem pelo homem. Por fim, expõem-se algumas contradições evidenciadas no Programa Mais Educação e nos Projetos de Lei intitulados Escola sem Partido.
\end{abstract}

Palavras-chave: Educação desinteressada. Educação integral. Antonio Gramsci. Programa Mais Educação. Escola sem partido.

\section{DISINTERESTED EDUCATION AND ANALYSIS OF EDUCATION POLICIES}

\begin{abstract}
This text aims to present Antonio Gramsci's thoughts on disinterested education for the integral education of students with the purpose of contributing to the analysis of ongoing proposals, programs and educational projects in Brazilian policies. To do so, based on bibliographic research, we rescued and interpreted the writings of the Sardinian thinker in order to find evidence of the need for a disinterested education that contributes to overcome the current social organization based on the exploitation of man-by-man. Finally, we present some contradictions evidenced in the Programa Mais Educação (More Education Program) and the Senate Bill entitled School without Party.
\end{abstract}

Keywords: Disinterested education. Integral education. Antonio Gramsci. Programa Mais Educação. Escola sem partido.

\section{EDUCACIÓN DESINTERESADA Y EL ANALISIS DE LAS POLITICAS EDUCATIVAS}

\section{Resumen}

Este texto tiene por objetivo presentar el pensamiento de Antonio Gramsci sobre la educación desinteresada para la formación integral de los estudiantes con el objetivo de contribuir al análisis de propuestas, de programas y de proyectos educativos en curso en las 
políticas brasileñas. Para ello, a partir de investigación bibliográfica, se rescatan e interpretan los escritos del pensador sardo para evidenciar la necesidad de una educación desinteresada que contribuya a la superación de la actual organización social basada en la explotación del hombre por el hombre. Por último, se exponen algunas contradicciones evidenciadas en el Programa Más Educación y en los Proyectos de Ley titulado Escuela sin Partido.

Palabras clave: Educación desinteresada. Educación Integral. Antonio Gramsci. Programa Mais Educação. Escola sem partido.

\section{INTRODUÇÃO}

O desenvolvimento do capitalismo, a partir do século XIX, mudou as relações sociais, econômicas e políticas, fazendo emergir novas necessidades em todos os setores da sociedade. A busca pela ampliação do capital e o desenvolvimento das tecnologias de produção exigiram a reorganização do Estado, do trabalho, da sociedade, das famílias e da educação. Na sociedade capitalista, as relações econômicas sobrepõem-se às sociais, impondo uma nova organização do trabalho e da vida dos indivíduos. As relações, até então naturais, tornam-se prioritariamente sociais, de forma que o direito natural não é mais o organizador das relações, as quais passam a ser regidas pelo direito positivo; ou seja, o contrato é o grande definidor da vida em sociedade. Nessa nova realidade, o Estado assume, pela coerção ou consenso, a defesa dos interesses de determinada classe, criando ou reorganizando o aparato legislativo; o trabalho ganha status de assalariado, evidenciado a liberdade dos trabalhadores para a venda de sua força em troca de um salário; as famílias reorganizam-se para garantir a subsistência segundo a lógica do trabalho industrial, parcial e alienado; e a educação alça um patamar de importância, visto que as novas exigências trazidas pelo desenvolvimento tecnológico-industrial reclamam um trabalhador de novo tipo, com conhecimentos até então desnecessários. Nesse contexto, as relações sociais amparam-se nos princípios revolucionários burgueses de igualdade e de liberdade.

É importante lembrar que o liberalismo, como fundamento da sociedade moderna, tem na liberdade a sua sustentação, visto que advoga a liberdade entre os indivíduos, tornando-os iguais de direito, mas não de fato. A propriedade, ao mesmo tempo que iguala por direito todos os indivíduos, na realidade os distancia. Enquanto a propriedade dos meios de produção fica nas mãos do capitalista, a propriedade da força de trabalho é do trabalhador, sendo este livre para dispor dela e aquele livre para explorá-la até o limite da força humana. Essa lógica põe em relevo a igualdade e a liberdade, em que todos se tornam iguais porque têm o direito à propriedade (dos meios de produção ou da força de trabalho) e livres porque podem dispor dela quando e como julgarem apropriado, sem evidenciar as contradições inerentes à questão. Nessa perspectiva, Marx já alertou, em 1847, que a força 
Artigo

doi: $10.20396 /$ rho.v18i3.8652086

de trabalho do trabalhador se converte em mercadoria no processo de produção capitalista, evidenciando a grande distância existente entre a propriedade dos meios de produção e a propriedade da força de trabalho.

\begin{abstract}
A força de trabalho é, assim, uma mercadoria que seu possuidor, o assalariado, vende ao capital. Por que a vende? Para viver.

Mas a força de trabalho em ação, o trabalho mesmo é a atividade vital peculiar ao operário, seu modo peculiar de manifestar a vida. E é esta atividade vital que ele vende a um terceiro para assegurar-se dos meios de subsistência necessários. Sua atividade vital não lhe é, pois, senão um meio de poder existir. Trabalha para viver. (MARX [1847], s/d, p. 63).
\end{abstract}

Enquanto o trabalhador trabalha para [sobre]viver vendendo sua força de trabalho, o capitalista vive da exploração desse trabalhador. Podem os dois ser, de fato, iguais e livres? Nessa lógica, a igualdade e a liberdade apresentadas, em princípio, como positivas, tornam-se contraditórias, pois não interferem na organização social posta e, ainda, ao naturalizar e individualizar tais pressupostos, maximizam a desigualdade de classe fortalecendo a exploração de uma classe sobre a outra. A igualdade e a liberdade tornam-se falsetes travestidos de verdade. Desmistificar essa realidade de forma a colaborar na consciência coletiva sobre a imprescindibilidade de sua superação precisa ser uma das tarefas fundamentais da educação e da escola.

Por isso, pensar uma educação que contraponha a hegemonia capitalista é fundamental para fortalecer os interesses daqueles que vêm tendo seu direito, de usufruir da vida em toda sua plenitude, usurpado em prol da ampliação acelerada do capital. Nessa perspectiva, no presente texto, propomo-nos a refletir sobre a emergência de rever os pressupostos de uma educação desinteressada para contrapor aos interesses formativos evidenciados na educação que se submete às necessidades capitalistas. Tendo como âncora para a análise as reflexões nos escritos do pensador sardo Antonio Gramsci ${ }^{3}$, procuramos expor algumas contradições de duas propostas político-educacionais em curso no país: o Programa Mais Educação, já implementado em escolas públicas, e o teor do Projeto de Lei Escola sem Partido, em fase de discussão em várias casas legislativas.

\title{
EDUCAÇÃO INTERESSADA: COMPROMISSO COM O CAPITAL
}

O capitalismo e o avanço tecnológico contribuíram para que a centralidade da urbanização trouxesse consigo a necessidade de alterar a forma de ensinar e aprender. É por isso que a educação escolar passou a ser o modo dominante de educação na sociedade capitalista, mas não qualquer educação, mas sim aquela que estivesse ligada à ampliação da produção capitalista, ou seja, uma educação para o capital. Nesse contexto e sujeito à organização capitalista, que tem na dualidade de classes seu fundamento maior, a educação também é pensada para fortalecer essa forma de sociabilidade. Segundo Schlesener (2009, p. 166), “[...] não se pode ter ilusões quanto à tarefa da escola no modo de produção 
capitalista: é preparar para o trabalho nas condições que este se apresenta nessa sociedade." A educação, então, encontra-se dividida conforme a origem dos sujeitos que dela usufruem, ou, como dizia Gramsci (2006, p. 49), "[...] a marca social é dada pelo fato de que cada grupo social tem um tipo de escola próprio, destinado a perpetuar nesses grupos determinada função tradicional, diretiva ou instrumental." Nesse sentido, aos filhos do capitalista, uma oferta educacional assentada em conhecimentos que forme para funções de direção; enquanto aos filhos da classe trabalhadora, uma formação para a exploração da força de trabalho e para o trabalho assalariado, contribuindo, dessa forma, para a hegemonia capitalista.

Assim, a divisão de classes evidencia-se também na oferta escolar. Enquanto as condições e as oportunidades educacionais dos filhos do capitalista são ampliadas tanto no acesso à escola quanto no acesso aos conhecimentos mais amplos, os filhos da classe trabalhadora são privados de uma formação integral, adentrando cada vez mais cedo no processo de trabalho, para garantir a própria subsistência. Gramsci já alertava, em 1916, em texto publicado no L'Avanti! :

Um proletário, ainda que inteligente, ainda que com todas as condições necessárias para tornar-se homem de cultura, é obrigado a desperdiçar suas qualidades em outra atividade, ou a tornar-se um obstinado, um autodidata, ou seja, com as devidas exceções, um meio homem, um homem que não pode dar tudo o que poderia dar caso tivesse se completado e fortalecido na disciplina da escola. (GRAMSCI, 2004, p. 74).

A escola que privilegia um pequeno grupo e massifica a educação da maioria é considerada, segundo Gramsci (2004), uma escola "interessada", visto que tem um interesse imediato: formar um grupo dirigente para uma sociedade organizada sob pressupostos capitalistas e, ao mesmo tempo, molda os demais para o processo produtivo, mantendo a hegemonia da classe dominante. A educação democratizada por esse modelo de escola não interfere no modo de produção vigente e não possibilita um processo emancipatório, visto que a emancipação em uma perspectiva revolucionária necessita ser coletiva de forma a superar a atual forma de sociabilidade e instaurar outro modo de produção baseado no trabalho associado.

A esse respeito, considerando os limites da sociedade capitalista, Marx (2009a; 2010) esclarece que, nessa organização social, a única emancipação possível é a política, evidenciada no sufrágio universal, enquanto que uma emancipação humana só seria possível com a superação do capitalismo e do capital. Ao abordarem a questão, Lessa e Tonet (2011, p. 115) consideram a emancipação humana como "[...] possibilidade histórica [...]", visto que outra forma de sociabilidade será necessária para se alcançar a verdadeira igualdade e liberdade. Nessa perspectiva, mesmo representando um avanço no capitalismo, a emancipação política é limitada, pois é apenas formal e não real. Nesse contexto, permeada pelas limitações da organização social capitalista, a educação em uma 
perspectiva emancipatória apresenta os limites intransponíveis, reduzindo-se à forma imposta pela hegemonia da classe dominante, ou seja, uma educação interessada.

A educação interessada, no contexto capitalista, fundamenta-se em uma emancipação política e traz em seu bojo a ideologia à qual está visceralmente ligada. Para tanto, a partir do referencial materialista histórico e dialético, que fundamenta as reflexões acerca da educação interessada, caracterizamos alguns princípios que alicerçam a educação interessada segundo a hegemonia capitalista, orientando as propostas e os programas político-educacionais:

- Manutenção da dualidade estrutural da sociedade e da escola, por meio de um trabalho pedagógico ideologicamente comprometido com interesses de determinado grupo social. Esse grupo, que detém a hegemonia, não tem o compromisso de garantir formação cultural e humanística a toda à população, mas apenas àqueles que compactuam do mesmo pensamento e dos mesmos objetivos sociais, políticos e econômicos. Dessa forma, interesses, compromissos e objetivos do grupo hegemônico fortalecem-se e solidificam-se, e, por consequência, naturalizam as desigualdades de forma a culpar individualmente o sujeito por seu lugar na hierarquia social.

- Formação e manutenção de quadros para o aparelho produtivo capitalista: pautada na justificativa do desenvolvimento econômico do país visando alçar patamar elevado no contexto internacional, a educação forma um pequeno grupo de dirigentes e uma grande massa de trabalhadores, empregados ou não, que garantirão a lógica de exploração do trabalho e a ampliação da mais-valia.

- Trabalho cultural e transmissão de conhecimentos comprometidos com o desenvolvimento do capitalismo, sem considerar a cultura popular, criando um fosso quase intransponível para os filhos dos trabalhadores. Esse princípio, ao orientar a oferta educacional, retira dos trabalhadores a identificação cultural coletiva e de classe, deixando-os a mercê das orientações hegemônicas. Nesse sentido, desorienta a ação social e política dos trabalhadores, enfraquece a luta por direitos coletivos e, consequentemente, nega e impede o desenvolvimento de consciência de classe.

- A valorização máxima do capital, seja pela conquista hegemônica, que subordina a maioria aos interesses da minoria; seja pela coerção imposta pelo aparato econômico-jurídico-político, que dá amparo aos pressupostos capitalistas, de forma a possibilitar a exploração ampliada do trabalho, a extração da mais-valia e o aprofundamento das desigualdades.

Esses princípios que orientam a educação interessada são claros, bem delineados e articulados, interligam-se formando um todo coeso, orientando projetos e programas 
políticos para a área educacional. Isso só é possível porque há o consenso da sociedade civil, alcançado pelo exercício hegemônico da classe dirigente, que transforma os interesses dessa classe em interesses universais, de forma que as "[...] pessoas singulares expressem consciente e organicamente um bloco social nacional." (GRAMSCI, 2006, p. 93). Ocorre, então, o que Gramsci convencionou chamar de bloco histórico, expresso na unidade entre estrutura e superestrutura. "Este novo tipo de escola aparece e é louvado como democrático, quando, na realidade, não só é destinado a perpetuar as diferenças sociais, como ainda a cristalizá-las em formas chinesas." (GRAMSCI, 2006, p. 49). No entanto, isso só é possível em razão da hegemonia da classe dirigente sobre o conjunto da sociedade, tal qual alertou o pensador sardo ao expressar que, quando uma ideologia tende a prevalecer, esta se impõe e se irradia por toda a sociedade, de forma a determinar,

[...] além da unicidade dos fins econômicos e políticos, também a unidade intelectual e moral, pondo todas as questões em torno das quais ferve a luta não no plano corporativo, mas num plano "universal", criando assim a hegemonia de um grupo social fundamental sobre uma série de grupos subordinados. (GRAMSCI, 2007, p. 41, grifo do autor).

Por isso, uma educação voltada aos interesses hegemônicos na atual forma de sociabilidade, ou seja, organicamente interessada nos objetivos capitalistas, é aquela que, em detrimento das classes subalternas, se impõe como verdadeira, como única alternativa viável para toda a humanidade, sem mostrar seu potencial desumanizador. Paolo Nosella (1992, s/p) a considera “[...] interesseira, mesquinha, imediatista [...]", justamente por fazer do industrialismo seu princípio pedagógico e tornar a educação instrumento de trabalho. Assim sendo, a educação exerce função decisiva na atividade econômica e, ao formar tanto dirigentes quanto dirigidos para os interesses capitalistas, demonstra o quão contraditória pode ser a formação das novas gerações.

É sob essa lógica que as políticas educacionais brasileiras têm se assentado e que a organização escolar se mostra mais eficaz. No entanto, tal organização escolar, curricular e pedagógica não pode ser considerada a mais adequada aos filhos dos trabalhadores, visto que não possibilita a formação integral dos alunos e colabora para a manutenção de uma sociedade desigual, baseada na exploração, na injustiça social e cultural, além de colaborar para a manutenção dos ideais desse grupo específico em detrimento das necessidades e dos valores do grupo de trabalhadores.

Em contraposição a esse modelo hegemônico de educação, há outra forma defendida por Gramsci, que ele chamou de educação desinteressada, sobre a qual trataremos a seguir.

\section{EDUCAÇÃO DESINTERESSADA: COMPROMISSO COM A TRANSFORMAÇÃO DA REALIDADE}


O pensamento de Antonio Gramsci sobre a educação e a escola necessária para os grupos dirigidos vincula-se ao movimento social, político e econômico da época em que viveu. É importante destacar que ele viveu em um período conturbado da história mundial, um momento de entre guerras, que viveu uma revolução operária que marcou a vida dos trabalhadores e alavancou muitas reivindicações sociais. A necessidade de superar a crise econômica levou a mudanças estruturais no modo de produção, com a inserção de novas tecnologias e novos métodos de trabalho, que fez emergir um novo modo de vida ${ }^{5}$; no movimento em prol da conquista socialista no leste europeu que culminou com o término do Czarismo na Rússia ${ }^{6}$ e a consequente instauração de um governo revolucionário ${ }^{7}$; nos movimentos reformistas ou reacionários que ofereceram o lastro necessário para o fortalecimento do Fascismo na Itália e, posteriormente, do Nazismo na Alemanha.

Além dessa conjuntura europeia, a influência de uma das regiões mais pobres da Itália, o Mezzogiorno ${ }^{8}$, exerceu forte repercussão na forma como Gramsci desenvolveu seu pensamento acerca das questões econômicas, políticas, sociais e educacionais. A preocupação com a formação das massas trabalhadoras (operários e camponeses) foi uma constante no seu pensamento. Tanto que, ao longo de seus escritos, sejam aqueles publicados nos jornais e destinados a morrer ao final do dia, sejam aqueles escritos para sempre ou nas interlocuções feitas com a família por meio de cartas, a questão educacional muito preocupou o pensador revolucionário, fazendo com que, ao longo de sua existência, ele produzisse inúmeras reflexões a respeito da educação que contribuísse na formação de homens (e mulheres) capazes "[...] de pensar, de estudar, de dirigir ou de controlar quem dirige." (GRAMSCI, 2006, p. 49).

Não vamos nos ater à imensa gama de reflexões propostas por Gramsci, mas centrar a reflexão sobre os fundamentos de uma educação desinteressada, como necessidade primeira para a formação de pessoas capazes de compreenderem seu lugar na atual forma de sociabilidade e, a partir dessa compreensão, que não é individual, mas coletiva, proporem outra forma de vida. No entanto, conforme já nos ensinou o cânone da filosofia da práxis, é preciso ter claro que:

\footnotetext{
Nenhuma formação social desaparece antes que se desenvolvam todas as forças produtivas que ela contém, e jamais aparecem relações de produção novas e mais altas antes de amadurecerem no seio da própria sociedade antiga as condições materiais para a sua existência. Por isso, a humanidade se propõe sempre apenas os objetivos que pode alcançar, pois, bem vistas as coisas, vemos sempre que esses objetivos só brotam quando já existem ou, pelo menos, estão em gestação as condições materiais para sua realização. (MARX [1843], s/d, p. 302).
}

Essa reflexão proposta por Marx e revista por Gramsci no Caderno 13, quando este analisa as relações entre estrutura e superestrutura, auxilia-nos a entender a importância que a educação pode exercer, como componente superestrutural, na organização social e, quiçá, influenciar em um processo verdadeiramente revolucionário para a instauração de 
uma sociedade justa e igualitária, ou seja, a alteração do plano estrutural. A educação, portanto, não é pensada isolada da estrutura ou na superestrutura, mas na relação dialética, que envolve as questões econômicas, políticas e sociais, e, assim, se torna determinante para a consciência dos indivíduos, não sendo apenas instrutiva, mas formativa.

Nessa perspectiva, no Caderno 12, a instituição moderna responsável pela educação das novas gerações é apresentada como formadora de intelectuais, tradicionais ou orgânicos, que lutarão pela hegemonia de uma ou outra classe social. É nesse escrito que Gramsci propõe uma escola “[...] fundamentada 'desinteressadamente' no trabalho moderno industrial” (MONASTA, 2010, p. 50, grifo do autor), e que tenha sua organização em uma "[...] escola única inicial de cultura geral, humanista, formativa, que equilibre de modo justo o desenvolvimento da capacidade de trabalhar manualmente (tecnicamente, industrialmente) e o desenvolvimento das capacidades de trabalho intelectual." (GRAMSCI, 2006, p. 33).

Assim, a educação desinteressada situa-se diametralmente oposta aos pressupostos da educação interessada, por ser aquela que objetiva a formação omnilateral do ser humano, resgatando a essência metodológica e humanística da escola tradicional, tornando a escola moderna em uma escola orgânica. Por isso, para não cair em retórica vazia, o termo desinteressado utilizado por Gramsci precisa ser entendido para além do significado literal. A esse respeito, Nosella (1992, p. 18, grifo do autor) esclarece que a expressão desinteressada revela a contraposição de uma curta visão imediatista e oportunista resgatando o sentido de "[...] 'cultura desinteressada', como sendo uma cultura de ampla visão, séria, profunda, universal e coletiva, que interessa a todos os homens." Entretanto, é preciso ter claro que uma cultura que interesse a todos os homens não representa o objetivo coletivo na atual forma de sociabilidade. Gramsci desenvolve, com as reflexões sobre a educação desinteressada, um complexo arcabouço teórico e ideológico altamente revolucionário, que traz a latência de uma sociedade a ser perseguida, demonstrando a relação dialética do seu pensamento, não separando, mas relacionando as questões sociais, políticas e econômicas por meio da educação. Ou seja, a educação nesse caminho não é neutra, mas amplamente comprometida com a formação de novos dirigentes, tendo a formação omnilateral como princípio e a superação da sociedade capitalista como fim.

Ao longo de seus escritos, Gramsci delineia, portanto, a forma como a escola deveria ser organizada para atender aos pressupostos de uma educação desinteressada conforme interpretação italiana ${ }^{9}$, culminando com a escrita militante do texto Homens ou Máquinas?, publicado em 1916, no L'Avanti. Nesse texto, o autor polemiza acerca da discussão ocorrida na Câmara de Vereadores de Turim a respeito da educação profissional mantida pela Prefeitura, na qual dois princípios antagônicos estavam em jogo: “[...] de um lado a educação discriminante do vereador Sincero contra a educação unitária e democrática de Zini” (NOSELLA, 1992, p. 19), expondo que: 1. A escola deveria ser de acesso irrestrito a todos, "[...] qualquer que seja sua condição econômica", questão ainda 
não evidenciada no programa escolar do Partido Socialista Italiano; 2. As condições materiais determinam a exclusão escolar do proletariado; e 3. Clama por uma escola de cultura desinteressada para o todo o proletariado (GRAMSCI, 2004). Segundo o revolucionário sardo, essa seria " $[$...] uma escola na qual seja dada à criança a possibilidade de ter uma formação, de tornar-se homem, de adquirir aqueles critérios gerais que servem para o desenvolvimento do caráter." (GRAMSCI, 2004, p. 75). No entanto, o que ele propõe então?

A partir da proposição de Antonio Gramsci, é possível indicar que a escola desinteressada, necessária aos trabalhadores, precisaria ser sólida de modo a alicerçar a formação geral sem priorizar a profissional. Para tanto, em relação à formação geral, a todos deveriam ser dadas as condições para o acesso aos conhecimentos relativos à filosofia, às ciências, às artes, à gramática, à literatura, etc., de modo a oferecer cultura geral e criar bases para o avanço de novos conhecimentos. O trabalho pedagógico deveria primar pela autonomia, de modo a contribuir para que o indivíduo pudesse agir conforme sua vontade, sem constrangimentos e sem metas prefixadas. Nesse sentido, uma escola de e para a liberdade, tanto individual quanto coletiva. Assim, todos teriam diante de si “[...] todas as possibilidades, todos os terrenos livres para poder realizar sua própria individualidade do melhor modo possível e, por isso, do modo mais produtivo para eles mesmos e para a coletividade." (GRAMSCI, 2004, p. 75). Da mesma forma, a formação profissional "[...] não deve se tornar uma incubadora de pequenos monstros aridamente instruídos para um ofício, sem ideias gerais, sem cultura geral, sem alma, mas só com o olho certeiro e mão firme" (GRAMSCI, 2004, p. 75), podendo também ter a cultura educativa como eixo condutor. No sentido proposto, a formação humanística e as orientações para o trabalho fazem parte de um todo orgânico, colaborando para alterações estruturais na sociedade. Apreende-se, portanto, que a educação desinteressada proposta é engajada com o planejamento coletivo, tendo objetivos sociais, políticos e econômicos vinculados à outra forma de sociabilidade, considerando a formação integral do indivíduo e não apenas o preparo para funções práticas voltadas à produção.

Ao discutir com Iulca em carta de 1932 sobre sua atuação como artista desinteressada, Gramsci (2005, p. 180) esclarece que o termo "[...] não significa plantada nas nuvens", mas "interessada" para além do sentido imediato e mecânico da palavra, ou seja, comprometida com a formação integral dos sujeitos na coletividade; uma escola na qual a formação e atuação artística não tem um interesse imediato, sendo por isso desinteressada, mas altamente interessada no desenvolvimento da sensibilidade humana. Em uma formação omnilateral, esse aspecto do processo formativo é essencial para o conjunto dos homens.

Em relação ao significado de uma formação omnilateral, Manacorda (2007) esclarece, a partir dos escritos de Marx, que, nessa perspectiva, persegue-se o resultado de tornar os jovens "[...] disponíveis para alternar a sua atividade, de modo a satisfazer tanto 
as exigências da sociedade quanto as suas inclinações pessoais", recuperando a "[...] unidade da sociedade humana em seu todo e da onilateralidade [sic] do homem singular, numa perspectiva que une, ainda que num rápido aceno, fins individuais e sociais, homem e sociedade." (MANACORDA, 2007, p. 38).

A formação omnilateral, como ápice de tornar a necessidade virtude, representa

[...] a chegada histórica do homem a uma totalidade de capacidades produtivas e, ao mesmo tempo, a uma totalidade de consumos e prazeres, em que se deve considerar sobretudo o gozo daqueles bens espirituais, além dos materiais, e dos quais o trabalhador tem estado excluído em consequência da divisão do trabalho. (MANACORDA, 2007, p. 89-90).

Apreende-se, portanto, que a educação desinteressada é aquela que prepara dialeticamente o indivíduo para agir em prol da superação do modo de produção capitalista, considerando os limites desta e as possibilidades para usufruir a vida em outra sociedade, de modo a produzir os bens materiais e culturais para uma vivência verdadeiramente livre. A educação desinteressada fundada na omnilateralidade não é uma utopia mas uma possibilidade histórica que se une ao compromisso social, político e econômico de superar a sociedade organizada segundo o modo de produção capitalista, ou seja, tem objetivo de tornar possíveis os limites até então considerados intransponíveis: de uma sociedade dividida em classes para uma sociedade coletiva, do trabalho explorado para o trabalho associado, do capitalismo para o socialismo (mas não o socialismo deturpado que não conseguiu superar os interesses econômico-corporativos e sim àquele sob à égide dos interesses universais). Com vistas à transformação radical da sociedade, a escola, sob os pressupostos da educação desinteressada, objetiva o desenvolvimento de todas as potencialidades do indivíduo, tanto as de natureza humanística, técnico-científica quanto profissional, relacionando-as organicamente.

Nesse sentido, Jesus (2005) interpreta o termo "desinteressado" da seguinte forma:

\footnotetext{
“Desinteressado" não quer dizer neutro ou indiferente. Deve ser também afastada a conotação pejorativa de pouco interesse, de descaso. Pelo contrário, uma escola "desinteressada" vai significar que ela tem a função de formar "onilateralmente" [sic] os homens. Exige-se desse tipo de escola que ela desenvolva as possibilidades e as tendências da criança, sem preocupação com a especialização. A escola "desinteressada" tem como grande perspectiva pedagógica "a formação de Homens superiores". (JESUS, 2005, p. 58, grifos do autor).
}

A educação desinteressada é, necessariamente, aquela que tem como horizonte o futuro dos homens e da sociedade, radicalmente fundado no presente. Segundo Nosella (2013, p. 52, grifos do autor), Gramsci conseguiu transformar '[...] a relação 'interessada' da política em relação 'desinteressada', pedagógica, educativa; ao mesmo tempo, transformou a relação idealista e redentora da educação em atividade política, de direção, de hegemonia." Nesse sentido, a educação ultrapassa os muros escolares e torna-se viva no 
Artigo

doi: $10.20396 /$ rho.v18i3.8652086

seio da sociedade, deixa de ser voltada exclusivamente para a produção e se volta para formação integral do homem, ou seja, forma homens cultos, sensíveis e não apenas, mas também, produtivos, chegando ao que Gramsci convencionou chamar de "novo intelectual". Segundo Gramsci (2006, p. 53, grifo do autor), esse novo intelectual terá uma "[...] inserção ativa na vida prática, como construtor, organizador, 'persuasor permanentemente", por isso ele defende uma educação que transponha os interesses imediatos "[...] da técnica-trabalho, chega à técnica-ciência e à concepção humanista histórica, sem a qual permanece 'especialista' e não se torna 'dirigente' (especialista + político)" (GRAMSCI, 2006, p. 53, grifos do autor).

De acordo com Nosella (2013, p. 51), Gramsci marcou profundamente o pensamento pedagógico até então existente, superando "[...] em raiz a dualidade escolasociedade", pois ultrapassou "[...] os limites conceituais da sociologia da educação tradicional, que entendia a educação como um reflexo da sociedade ou um instrumento que prepara homens, técnicos, para entrarem na sociedade [...]." Dessa forma, a educação assume a dimensão essencialmente política.

A defesa de uma educação desinteressada, conforme proposto por Gramsci, mexe com os princípios pedagógicos que orientam a oferta educacional hegemônica, pois exige a reorganização pedagógica, curricular, formação inicial e continuada de professores, além de políticas públicas que garantam a permanência das crianças e dos jovens no processo formativo ${ }^{10}$. A lógica que permeia o atual modo de produção e a atuação do Estado (sociedade civil + sociedade política) não permite que isso aconteça, visto que essa forma de entender a educação e atuar no processo educativo só poderá alcançar a plenitude com a instauração de uma sociedade livre.

No entanto, ao ter-se clareza sobre os limites impostos pelo modo de produção capitalista, é possível pensar em ações que colaborem para o desenvolvimento de uma educação desinteressada, a qual só alcançará plenitude quando as atuais formas econômicas, sociais e políticas estiverem definitivamente superadas. Mesmo cientes de que, no materialismo histórico e dialético, não é possível fixar atitudes para todas as realidades, elencamos, sob a luz dos pressupostos gramscianos de uma educação desinteressada, algumas ações/atitudes a serem perseguidas, mesmo sob os limites da atual forma de sociabilidade: a defesa incondicional sobre a necessidade de uma escola unitária, que considere as capacidades individuais imediatas e interesses coletivos mediatos; a garantia de financiamento público que assegure a permanência de todas as crianças e todos os jovens na escola; atividades curriculares e extracurriculares que possibilitem a inserção na cultura geral e que, ao mesmo tempo, valorize a cultura local; tempo necessário aos educadores para a formação e a inserção nas comunidades de forma que conheçam, debatam as realidades locais e seus destinos inseridos no contexto da humanidade em geral. Entendemos que, se essas ações se tornarem orientadoras do trabalho educativo a ser realizado, a educação ultrapassa o espaço escolar e se torna viva no seio da sociedade, 
orientando atitudes individuais e coletivas que tenham como horizonte a emancipação humana, tal qual abordado por Marx em Para a questão judaica.

\begin{abstract}
Só quando o homem individual retoma em si o cidadão abstrato e, como homem individual - na sua vida empírica, no seu trabalho individual, nas suas relações individuais -, se tornou ser genérico; só quando o homem reconheceu e organizou as suas forces propres (forças próprias) como forças sociais e, portanto, não separa mais de si a força social na figura da força política - [é] só então [que] está consumada a emancipação humana. (MARX, 2009a, p. 71, grifos do autor).
\end{abstract}

Nessa perspectiva, a emancipação humana torna-se o eixo norteador da educação desinteressada, sendo uma educação formativa de viés humanista, cultural, político e técnico-científico. Somente assim o horizonte aproxima-se e torna-se real. Marx esclarece sobre essa nova realidade da seguinte forma:

\footnotetext{
$\mathrm{Na}$ fase superior da sociedade comunista, quando houver desaparecido a subordinação escravizadora dos indivíduos à divisão do trabalho e, com ela, o contraste entre o trabalho intelectual e o trabalho manual; quando trabalho não for somente um meio de vida, mas a primeira necessidade vital; quando, com o desenvolvimento dos indivíduos em todos os seus aspectos, crescerem também as forças produtivas e jorrarem em caudais os mananciais da riqueza coletiva, só então será possível ultrapassar totalmente o estreito horizonte do direito burguês e a sociedade poderá inscrever em suas bandeiras: De cada qual, segundo sua capacidade; a cada qual, segundo suas necessidades. (MARX [1875], s/d, p. 214215).
}

Para Marx, essa nova sociedade precisa ser construída no interior das atuais relações de força e de dominação, no movimento revolucionário. Enfrentar a luta de classes em todas as suas dimensões é a condição para construir-se, no interior da sociedade vigente, novas relações de produção, de sociabilidade, de pensamento, base para uma nova forma de viver e de ser. O processo revolucionário é, também, um processo educativo: a educação desinteressada tem uma importância fundamental para a formação de uma nova consciência crítica, no sentido que Marx (2009b, p. 475) já colocava em um de seus primeiros escritos (Sobre a Filosofia do Direito de Hegel - Introdução): “[...] libertar o homem da ilusão para que ele pense, aja e configure sua realidade como alguém que reconquistou a razão [...]."

Uma das condições para vencer a subalternidade é pensar com novos padrões, fora da norma instituída pelo pensamento politicamente correto, pelo qual a dominação econômica se consolida pela concepção de mundo unificadora e subserviente. Somente uma educação desinteressada, no sentido acima exposto, pode criar o homem novo, um modo de pensar autônomo por meio de uma formação integral capaz de superar o individualismo vivido na sociedade burguesa, a fim de gerar as condições de compreensão de que, para que um homem seja livre, é necessário que todos o sejam. A tarefa educativa, no sentido amplo de formação humana, tem de nascer no seio da sociedade capitalista, a 
partir da compreensão clara de suas contradições e na superação e na transformação da atual forma de sociabilidade.

Como acentua Dias (2012, p. 92), a "[...] superação da cisão dirigentes-dirigidos é a questão da possibilidade da revolução." Essa superação realiza-se como processo educativo de apropriação da linguagem pelos subalternos, processo que articula a "[...] questão da historicidade da política vigente, capitalista, com os projetos de sua negação." (DIAS, 2012, p. 92). É nesse contexto que a educação desinteressada se mostra na denúncia dos limites de um discurso abstrato e ideológico e na acentuação da necessidade de se buscar um universal que se converta em modo de vida, em uma nova ordem social e política. Por isso, Gramsci (2007, p. 19) questionava que:

Pode haver reforma cultural, ou seja, elevação civil das camadas mais baixas da sociedade, sem uma anterior reforma econômica e uma modificação na posição social e no mundo econômico? É por isso que uma reforma intelectual e moral não pode deixar de estar ligada a um programa de reforma econômica [...].

Nessa perspectiva, uma educação desinteressada precisa explicitar a articulação entre econômico, social, político e ideológico, para que se possa entender a estrutura de dominação da sociedade capitalista, esclarecer as novas configurações da luta de classes e criar, no interior desta sociedade velha e barbárica, as condições de uma nova sociabilidade.

\section{PARA CONCLUIR: RELAÇÕES ENTRE O PENSAMENTO DE ANTONIO GRAMSCI E PROPOSTAS POLÍTICO-EDUCACIONAIS}

Os pressupostos apresentados auxiliam na análise de programas e de projetos educacionais em curso no Brasil, os quais são planejados e efetivados conforme determinados interesses, nem sempre explícitos para a maioria da população. Uma das propostas que têm encontrado guarida em diferentes esferas da administração pública é a de ampliação do tempo de permanência de alunos no espaço escolar, denominada escola de tempo integral e, por vezes, equivocadamente apontada como educação integral. Na esfera federal, essa proposta materializou-se por intermédio do Programa Mais Educação, e, por meio da adesão de estados e municípios, disseminou-se em todo o país. Mesmo que a proposta governamental de ampliação do tempo de permanência dos alunos na escola tenha a educação integral exposta em seus fundamentos, consideramos que esta pouco ou nada tem da ideia gramsciana de educação integral, a qual toma uma conotação precisa nos escritos do político sardo.

Para Gramsci, trata-se de uma educação que possibilite desenvolver todas as capacidades individuais a partir da inserção dos sujeitos em projetos coletivos que viabilizem a criação de um novo modo de vida e de sociabilidade. Uma educação 
Artigo

doi: $10.20396 /$ rho.v18i3.8652086

produzida com base na efetiva igualdade social, a fim de implementar e fortalecer os laços coletivos a partir dos quais se instaura a verdadeira liberdade.

Um processo de educação integral seria, da perspectiva gramsciana, um meio de emancipação política e humana, a ser implementado a partir das condições sociais e políticas vigentes, para transformá-las. Efetivar esse processo de educação integral suporia superar os limites do individualismo ao qual somos reduzidos na sociedade capitalista.

Propor educação integral sem questionar a estrutura econômica nascida e mantida pela exploração e pela expropriação do trabalho e sem questionar as várias formas de dominação existentes significa partir já de um contexto extremamente limitado. Sem um projeto de sociedade claramente definido e sem planejamento preciso que possibilite uma efetiva mudança no processo educativo não se chega muito longe.

O significado de educação integral depende do projeto político que se queira implantar ou conservar. A história da educação brasileira está marcada por várias iniciativas e estratégias de implementação de educação integral "inspiradas em diferentes concepções pedagógicas". Diversas experiências foram realizadas, das quais salienta-se: Anísio Teixeira (1934); a Escola Parque da Bahia (1950), estendidas depois a Brasília; tentativas de Darcy Ribeiro (1983, 1986 e 1991-1994), Leonel Brizola e outros (SILVA; SILVA, 2012, p. 51).

O Programa Mais Educação ${ }^{11}$ surgiu em 2007 e insere-se no Programa de Desenvolvimento da Educação (PDE) dos governos petistas, que visa melhorar a qualidade da educação pública. No corpo da Portaria Interministerial que implementa o Programa, a ideia de educação integral tem inspirações teóricas ambíguas, de acordo com o próprio projeto político do Partido dos Trabalhadores - PT. No conjunto, identifica-se a "[...] concepção pragmatista de educação, presente nas experiências anteriormente vividas no Brasil", com "[...] algumas inovações/ ressignificações em relação ao ideário da escola nova." (SILVA; SILVA, 2012, p. 82).

Mesmo se definindo como um partido de esquerda, o PT optou pela governabilidade e não pela mudança radical da estrutura econômica, social e política brasileira. As ambiguidades e as contradições que podem ser identificadas nesse Programa fazem parte de ações de um governo que, ao mesmo tempo que procura implementar políticas de abertura de acesso à educação para as classes trabalhadoras pela expansão do Ensino Médio e Superior gratuito, incentiva o crescimento da rede privada de ensino. Nesse contexto, o Programa Mais Educação insere-se no Programa Todos pela Educação, inspirado por empresários liberais que pretendiam envolver o governo e a sociedade civil em geral em um compromisso pela melhoria da educação, imediatamente comprometida com as demandas do capital. Não se trata, portanto, de uma formação integral efetiva dos sujeitos, nem de questionar a estrutura econômica e social vigente, mas de ampliar a jornada escolar, mantendo o aluno mais tempo na escola, sem alterar currículos ou ampliar 
instalações já precárias. A intenção implícita era de transferir para a comunidade parte da responsabilidade educativa, envolvendo a família e partilhando o espaço de outras instituições da comunidade, do bairro ou da cidade, como praças, clubes esportivos, para desenvolver o que o Programa denomina ação integrada com a comunidade.

As políticas educacionais em geral (e esta, em particular) apresentam, ainda, uma ambiguidade teórica que se evidencia na mistura de ideias de paradigmas diferentes que se disseminam no conjunto de publicações produzidas para definir educação integral e orientar o trabalho pedagógico. Silva e Silva (2012, p. 93) identificaram a influência liberal pragmática, da Escola Nova, da antropologia cultural, do culturalismo, na forma de uma "[...] educação integral intercultural, que guia o Programa Mais Educação, o valor da diversidade, da pluralidade e da diferença" que, na perspectiva da abordagem, tem a "[...] função necessária para a empregabilidade em relação ao capitalismo flexível, já na educação básica." (SILVA; SILVA, 2012, p. 93).

Assim, o uso do termo Educação Integral em Tempo Integral pode gerar equívocos se não se explicitam os conteúdos dos programas educacionais e dos projetos políticos dos quais os programas emanam. A sociedade capitalista, na ação de seus intelectuais, apropria-se de conceitos e das reivindicações da classe trabalhadora modificando-os e assim se mantendo como dirigente. Associar emancipação (política e cultural) do indivíduo ao empreendedorismo do projeto neoliberal apresenta-se como uma das contradições que o uso do termo Educação Integral consegue ocultar. Ao se explicitarem as relações e os objetivos assim mascarados, percebe-se que se trata de inserir o jovem no sistema produtivo ou, se muito, tirar o jovem da rua e preencher o seu tempo com atividades simples que não se constituem, efetivamente, como formação humana.

Outra questão candente que gera polêmica no âmbito da educação é o projeto de lei conservador denominado Escola sem Partido: a ideia defendida é de uma escola que prime pela neutralidade. A questão vem sendo colocada desde 2004, e, atualmente, se materializa em vários Projetos de Lei em tramitação por todo o país. Os proponentes partem da ideia de que existe uma doutrinação ideológica de esquerda nas escolas públicas, com um discurso antirreligioso e de gênero, que precisa ser banido. Ou seja, pretende-se a neutralidade, mas sendo, em uma sociedade dividida em classes sociais antagônicas, construída com base na exploração da força de trabalho, essa neutralidade não existe. A própria proposição é contraditória em termos porque, se uma esquerda é reconhecida, deve-se reconhecer também uma direita, que é a perspectiva na qual os proponentes se colocam.

O que se esconde por trás desse projeto é uma educação comprometida com os interesses econômicos, sociais e políticos vigentes, uma escola doutrinadora, sem crítica, que referende a ordem instituída e não mostre aos alunos as contradições e os problemas sociais que todos enfrentamos. Uma educação interessada é doutrinadora e ideológica, ou 
seja, apresenta determinadas teorias como a verdade absoluta porque são ideias sem contexto e sem história. Trata-se de uma perspectiva parcial (interessada ou comprometida com uma perspectiva) apresentada como universal e inquestionável.

Defender uma educação crítica é defender uma educação desinteressada. O que é o pensamento crítico? É o pensamento que reconhece sua historicidade e, como tal, esclarece que fala de uma determinada perspectiva (que pode ser um método racional, como em Kant, ou o método dialético, como o de Hegel, ou ainda uma posição de classe, como a de Marx). E, na medida em que se reconhece a historicidade, pode-se também reconhecer as contradições a serem superadas para se alcançar uma visão abrangente e passível de ser apropriada por todos.

Uma educação desinteressada é uma educação comprometida com a formação humana integral, com a transformação da sociedade, com a elevação cultural dos subalternos, a fim de criar as condições reais de passagem molecular dos dirigidos para a condição de dirigentes, passagem que, na democracia burguesa, é apenas uma promessa mistificadora que garante a perpetuação do status quo.

A educação desinteressada produz-se como formação humana, na perspectiva de que toda relação de hegemonia é uma relação pedagógica (GRAMSCI, 2007), um aprendizado permanente na interlocução constante com os outros e com a natureza. A educação desinteressada é integral e, portanto, não pode deixar de ser política, ou seja, marcada pela luta de classes enquanto existir a sociedade capitalista.

\section{REFERÊNCIAS}

DIAS, E. F. Revolução passiva e modo de vida. São Paulo: Sundermann, 2012.

GRAMSCI, A. Cadernos do cárcere. Rio de Janeiro: Civilização Brasileira, 2006. 2 v.

GRAMSCI, A. Cadernos do cárcere. Rio de Janeiro: Civilização Brasileira, 2007. 3 v.

GRAMSCI, A. Cartas do cárcere [1931-1937]. Rio de Janeiro: Civilização Brasileira, 2005. 2 v.

GRAMSCI, A. Homens ou máquinas? In: Escritos políticos [1910-1920]. Rio de Janeiro: Civilização Brasileira, 2004. p. 73-75. 1 v.

JESUS, A. T. O pensamento e a prática escolar de Gramsci. 2. ed. Campinas: Autores Associados. 2005.

LEPRE, A. O prisioneiro: a vida de Antonio Gramsci. Rio de Janeiro: Record, 2001.

LESSA, S.; TONET, I. Introdução à filosofia de Marx. São Paulo: Expressão Popular, 2011. 
MANACORDA, M. A. Marx e a pedagogia moderna. Campinas: Alínea, 2007.

MARX, K. Crítica ao Programa de Gotha [1875]. In: MARX, K.; ENGELS, F. Obras escolhidas. São Paulo: Alfa-ômega. s/d. p. 203-234. 2 v.

MARX, K. Glosas críticas marginais ao artigo: o rei da Prússia e a reforma social. De um prussiano. São Paulo: Expressão Popular, 2010.

MARX, K. Para a questão judaica. São Paulo: Expressão Popular, 2009a.

MARX, K. Prefácio à “contribuição à crítica da economia política” [1843]. In: MARX, K.; ENGELS, F. Obras escolhidas. São Paulo: Alfa-ômega. s/d. p. 300-303. 1 v.

MARX, K. Sobre a crítica da Filosofia do Direito de Hegel. Introdução. In: MARCAL, J. (Org.). Antologia de textos filosóficos. Curitiba: SEED-PR, 2009b. p. 474-489.

MARX, K. Trabalho assalariado e capital [1847]. In: MARX, K.; ENGELS, F. Obras escolhidas. São Paulo: Alfa-ômega. s/d. p. 52-82. 1 v.

MONASTA, A. Antonio Gramsci. Tradução Paolo Nosella. Recife: Fundação Joaquim Nabuco, Massangana, 2010.

NOSELLA, P. A escola de Gramsci. Porto Alegre: Artes Médicas Sul, 1992.

NOSELLA, P. Controvérsias marxistas sobre a leitura e recepção de Gramsci na educação brasileira. In: LOMBARDI, J. C.; MAGALHÃES, L. D. R.; SANTOS, W. S. (Org.).

Gramsci no limiar do século XXI. (edição digital). Campinas: Librum, 2013. p. 45-59.

Disponível em:

<https://docs.wixstatic.com/ugd/35e7c6_c6a8ebab16b4414d8c26cd675310b0fb.pdf >. Acesso em: 05. out. 2017.

SCHLESENER, A. H. A escola de Leonardo: política e educação nos escritos de Gramsci. Brasília: Liber Livro, 2009.

SILVA, J. A. A.; SILVA, K. N. P. Educação integral no Brasil de hoje. Curitiba: CRV, 2012.

Notas

\footnotetext{
${ }^{1}$ Doutora em Educação Pela Universidade Federal de São Carlos - UFSCar. Docente do Departamento de Educação e do Programa de Pós-Graduação em Educação da Universidade Estadual de Ponta Grossa UEPG.

${ }^{2}$ Doutora em História pela Universidade Federal do Paraná - UFPR. Docente da Universidade Federal do Paraná no período de 1976 a 2005. Atualmente é docente do Programa de Pós-Graduação da Universidade Tuiuti do Paraná - UTP.

${ }^{3}$ Antonio Gramsci, nascido na Sardenha em 1891, foi um homem que, pautado na defesa dos trabalhadores (operários e camponeses) e no estudo dos pensadores, das ações dos governantes e das transformações sociais mundiais em curso nas primeiras décadas do século XX, procurou refletir profundamente sobre as
} 
contradições da época, deixando para a humanidade um legado de reflexões acerca dos valores humanos, morais, políticos e econômicos que o circundava. A partir do estudo sobre a obra de diferentes pensadores e do compromisso teórico-prático com o pensamento socialista, ele se tornou referência obrigatória para militantes e pesquisadores vinculados à esquerda, orientando a análise, o planejamento e a ação política em diferentes pontos do planeta. Em que pese a importância e a influência de Antonio Gramsci para a compreensão da realidade, não devemos buscar nele as respostas para os problemas presentes, mas ancorar nossas reflexões em seus escritos (os quais têm o limite do tempo histórico em que foram produzidos). Por isso, seus escritos são tomados como auxiliar para a compreensão do presente e não como receituário inquestionável e detentor de soluções para as mazelas atuais.

${ }^{4} \mathrm{O}$ L'Avanti era o órgão oficial do Partido Socialista em Turim. Nele, Antonio Gramsci publicou vários textos (quase um por dia), que tramitavam da crítica teatral à crônica citadina. Neles, o autor desenvolvia a articulação entre a teoria e a realidade político-social da época. Os escritos desse período podem ser considerados como um prenúncio do grande escritor que se tornaria no cárcere. (LEPRE, 2001).

${ }^{5}$ Sobre esse novo modo de vida é importante destacar as reflexões de Gramsci realizadas no texto Americanismo e Fordismo, escrito em 1934.

${ }^{6}$ Em março de 1917, o Czar Nicolau II foi deposto, sendo instaurado um governo provisório de caráter liberal burguês, o qual estava sob a responsabilidade de parlamentares (em especial formado por membros do Partido Menchevique) por um lado e, de outro, pelos Sovietes (membros dos Conselhos Revolucionários eleitos pelos trabalhadores, soldados e camponeses). Essa fase da Revolução Russa é conhecida como Revolução Branca.

${ }^{7}$ Em outubro de 1917 (novembro no calendário ocidental), ocorreu a chamada Revolução Vermelha, quando o governo provisório foi deposto por um movimento liderado por Lênin, sendo instaurado um novo período sob a responsabilidade do partido Bolchevique.

${ }^{8}$ Essa região corresponde às regiões do Sul da Itália (Molissa, Campagna e Puglia, Basilicato e Calábria), parte da Itália Central (no Lácio: Latina, Fronsionone e Rieti, nas Marcas: Ascoli-Piceno) e Itália insular (Sardenha e Sicília). Gramsci nasceu e cresceu na Sardenha.

${ }^{9}$ Gramsci, em carta de 1932, esclarece a Iulca que, certa vez, defendeu "[...] com certo escândalo de sua parte, que os cientistas, na atividade deles, são 'desinteressados'. Você rebateu, muito sucintamente, que eles são sempre 'interessados'. Naturalmente eu falava em termos 'italianos' e, na cultura italiana, tinha em mente as teorias filosóficas do Prof. Loria, que interpretou o termo e a noção de 'interesse' num certo sentido pejorativo que, nas 'Teses de Feuerbach", é qualificado como schmutzig jüdisch, sordidamente judeu." (GRAMSCI, 2005, p. 179, grifos do autor).

${ }^{10}$ Entende-se que as políticas públicas que visem assegurar a permanência de crianças e de jovens na escola precisam ocorrer em conjunto com políticas sociais e econômicas mais amplas, as quais, necessariamente, precisariam garantir a satisfação das necessidades materiais da população como um todo, de modo a impedir a evasão escolar dos jovens que necessitam buscar condições materiais de existência própria e da família.

${ }^{11}$ O Programa Mais Educação foi instituído pela Portaria Interministerial $n^{\circ} 17 / 2007$, publicada no Diário Oficial da União em 26 de abril de 2007.

Submetido em: 29/03/2018

Aprovado em: 04/07/2018

Publicado em: 28/09/2018 